\title{
Impact of untreated dental caries on oral health-related quality of life of children with special health care needs
}

\section{Khawana FAKER(a) \\ Mônica Almeida TOSTES(a) Viviane Andrade Cancio de PAULA ${ }^{(a)}$}

(a) Universidade Federal Fluminense - UFF, School of Dentistry, Department of Pediatric Dentistry, Niterói, RJ, Brazil.

Declaration of Interests: The authors certify that they have no commercial or associative interest that represents a conflict of interest in connection with the manuscript.

\section{Corresponding Author:}

Khawana Faker

E-mail: khawana.faker@hotmail.com

https://doi.org/10.1590/1807-3107BOR-2018.vol32.0117

Submitted: May 21, 2018

Accepted for publication: August 01, 2018

Last revision: November 01, 2018

\begin{abstract}
The oral health status of children with special health care needs (SHCN) can affect their quality of life wich domains of the Brazilian version of the Early Childohood Oral Health Impact Scale (B-ECOHIS). A cross-sectional study was conducted in children with SHCN (aged 1 to 9 years), who underwent an oral examination for the assessment of dental caries severity. Parents/caregivers answered two questionnaires, one on oral health-related quality of life (OHRQoL) - B-ECOHIS, and one on socioeconomic characteristics. Statistical analyses were performed using the Kolmogorov-Smirnov test, MannWhitney U-test, Poisson regression, Point-biserial correlation coefficient, and Cronbach's alpha. A total of 128 children participated in the study and OHRQoL was affected in $68.75 \%$ of them. The function domain in the Child Impact Section (CIS) had a higher mean value. Caries severity was associated with worse quality of life $(p=0.001)$. Severe dental caries was associated with a negative impact on the OHRQoL of disabled children and of their families. The impact of untreated dental caries and severity of dental caries was associated with the CIS domains (except for the self-image/social interaction domain).
\end{abstract}

Keywords: Dental Caries; Disabled Children; Pediatric Dentistry; Oral Health; Quality of Life.

\section{Introduction}

Patients with special health care needs (SHCN) have significant limitations in both intellectual functioning and adaptive behavior as expressed in conceptual, social, and practical adaptive skills. ${ }^{1}$ Twentyfour percent of the Brazilian population is composed of people who have some kind of disability (auditory, visual, physical, and/or intellectual). According to the Census of the Brazilian Institute of Geography and Statistics (IBGE), 45 million people in Brazil have SHCN. ${ }^{2}$

Studies have shown that the oral health of disabled individuals is poor and that they badly need oral treatment, leading to an increased caries risk/susceptibility. ${ }^{3,4} \mathrm{~A}$ high caries prevalence has been reported among people with $\mathrm{SHCN} .{ }^{5,6,7,8}$ In Brazilian people with $\mathrm{SHCN}$, the higher prevalence of caries is associated with a negative impact. ${ }^{5,8,9}$ Investigations in healthy children have shown that health problems such as dental caries can affect a person functionally, psychologically, and socially, in addition 
to causing pain and discomfort. ${ }^{10,11,12,13}$ The assessment of oral health-related quality of life (OHRQoL) is more difficult in children with SHCN due to their limited understanding of what is being evaluated. Parents' perception of dental caries in intellectually disabled children has been examined, and the results have shown a significant impact of dental caries on parents' perception of the OHRQoL of children with intellectual disabilities. ${ }^{4,5,8,9}$ Untreated dental caries represents a real clinical problem and it is associated with poor quality of life, ${ }^{14,15}$ however, there is a paucity of research studies involving individuals with $\mathrm{SHCN}$.

In dentistry, specific sociodental indicators have been used to measure the extent to which oral changes affect quality of life and well-being. ${ }^{11,16,17}$ The Early Childhood Oral Health Impact Scale (ECOHIS) was designed to assess the OHRQoL of preschool children, where parents/caregivers answer the questionnaire as children lack the necessary cognitive skills to assess their own quality of life. ${ }^{16}$ Dental caries has been associated with specific quality of life domains, such as the impact on parents' distress ${ }^{15}$ and on children's social, functional, and psychological well-being. ${ }^{14,15}$

The prevalence of any impact on OHRQoL has been higher for intellectually disabled children with both low and high caries severity when compared with their caries-free counterparts. ${ }^{4}$ However, the relation between OHRQoL in children with SHCN and presence of untreated dental caries has not been described in the literature. There are some limitations that need to be addressed, such as the use of a convenience sample and a sample of subjects with higher prevalence of potential risk factors for poor oral health than the general population..$^{18}$ Therefore, the purpose of this study was to identify which domains of the ECOHIS (symptoms, function, psychological well-being, and self-image/social interaction) are affected by the presence of untreated dental caries in a sample of Brazilian children with SHCN. In this study, we hypothesized that untreated dental caries severity, measured by the number of caries, is associated with worse OHRQoL. In addition, another objective was to determine sociodemographic factors that may influence the quality of life of children and of their parents/caregivers.

\section{Methodology}

\section{Study population}

This cross-sectional study was conducted in accordance with the Strengthening the Reporting of Observational Studies in Epidemiology (STROBE) statement, ${ }^{19}$ which was adapted to our study design. A convenience sample was selected for this crosssectional study conducted with children with SHCN enrolled in the Acolher Project at the Fluminense Federal University, in Niterói, a town located in the metropolitan area of Rio de Janeiro, in southeastern Brazil, between August 2016 and December 2017. The inclusion criteria were age between 1 and 9 years and diagnosis of systemic disease, intellectual disability, congenital malformation, or other incapacitating disorders, such as Down syndrome, autistic spectrum disorder, cerebral palsy, sensory and communication disorders, HIV, and cancer, among others. No selection criteria were applied to these conditions. Subjects who were not able to cooperate due to their medical conditions, those children whose parents refused to give consent, and incomplete questionnaires (parents who failed to answer more than two items related to their children and one item related to the family ${ }^{11}$ ) were excluded from the study. Subjects whose legal guardians consented to their participation and those who gave consent themselves were eligible for the study.

A sample with 134 individuals is sufficient for the pre-calculated sample of 114 caregiver-child pairs, assuming a prevalence of child and family impact scores of $70.2 \%$ (pilot study) and $54 \%,{ }^{4}$ a $5 \%$ margin of error, and a $95 \%$ power. Another $17.5 \%$ was added to the sample size to account for missing answers or uncooperative children. A pilot study was carried out for the data collection of the main investigation to test the methodology and the understanding of the questionnaires. The pilot study was conducted in 57 children with SHCN (aged 1 to 9 years) and their parents/ caregivers, who were randomly selected from a database and not included in the main study. This pilot study allowed observing an impact on $70.2 \%$ of the sample and higher mean values in the Child Impact Section (CIS) function domain. 


\section{Data collection - Impact on children's OHRQoL and sociodemographic information}

Parents/caregivers were asked to answer the Brazilian version of the ECOHIS ${ }^{17,20}$ and fill out a form for collection of socioeconomic information, such as gender (male or female), child's age $\left(<6\right.$ and $\geq 6$ ), ${ }^{11}$ parent's/caregiver's schooling (years of study: $\leq 8$ years, $>8$ years $)^{8}$, and household income based on the Brazilian minimum wage (approximately US $\$ 284.80$ per month; categorized into < 2 Brazilian minimum wages [BMW] and $\geq 2 \mathrm{BMW}){ }^{13}$ The B-ECOHIS was used to assess the negative impact of the presence and severity of caries on the quality of life of children with SHCN. This questionnaire is composed of 13 items distributed between the CIS and the Family Impact Section (FIS). The CIS has four domains: symptoms, function, psychological well-being, and self-image/social interaction. The FIS has two domains: parental distress and family function. The scale has five answer options $(0=$ 'never', $1=$ 'hardly ever', 2 = 'occasionally', 3 = 'often', 4 = 'very often', $5=$ 'don't know') for recording how often an event has occurred in the child's life. ${ }^{16,1720}$ The 'don't know' answers are not counted..$^{12}$ The score for each domain is calculated through a simple sum of the scores of each item. The CIS and FIS scores are calculated through a simple sum of the scores of all items in each section, ranging from 0 to 36 (CIS) and from 0 to 16 (FIS). The total score ranges from 0 to 52, with higher scores denoting greater oral health impact and poorer OHRQoL. The primary outcome in the present study was the occurrence of any impact on OHRQoL (B-ECOHIS>0). ${ }^{4,13}$

\section{Data collection - Child's oral examination}

The clinical oral examination was conducted by two experienced examiners (KF - examiner 1 and VC - examiner 2) who had undergone a calibration exercise during which inter-examiner and intraexaminer kappa values were 0.87 to 0.96 and 0.89 to 0.92 for examiners 1 and 2, respectively. ${ }^{18}$ A visual examination was carried out with the assistance of a mouth mirror (PRISMA, São Paulo, Brazil) and a probe (Golgran, São Paulo, Brazil) in a dental chair under the light of a reflector.
The main explanatory variable in our study was the presence of untreated dental caries measured by the DMFT index (decayed, missing, and filled teeth), but only the component 'decayed - d/D' was used. ${ }^{14,15,21}$ Likewise, caries prevalence was calculated using untreated dental caries data.

The patients were classified based on severity of caries and presence of untreated dental caries, which considers the decayed $(\mathrm{d} / \mathrm{D})$ teeth. After that, the participants were categorized into two groups: children without untreated dental caries $(\mathrm{d}$ $+\mathrm{D}=0$ ) and children with untreated dental caries $(d+D>0)$. Severity was classified according to the number of untreated dental caries ( 0 free of caries; 1-2 moderate; and $\geq 3$ high), where the upper cutoff values corresponded to the Significant Caries Index in this population. ${ }^{22}$

\section{Statistical analysis}

The SPSS 20.0 statistical package (SPSS Inc., Chicago, USA) was used to analyze the data. Descriptive analysis (including frequency distribution) was performed for overall mean B-ECOHIS scores. Scores for the individual domains were analyzed for differences between oral conditions and socioeconomic and demographic factors. The independent variables also included sociodemographic characteristics (parent's/caregiver's schooling, household income) and characteristics of the children (sex and age). The dependent variable was the impact of dental caries on the quality of life of children with SHCN (total B-ECOHIS score).

The Kolmogorov-Smirnov test verified that the data followed a non-normal distribution. The nonparametric Mann-Whitney test was used. Poisson regression with robust variance was used for the multivariate analysis. The point-biserial correlation (Pearson's correlation) was used to compare age, sex, parent's/caregiver's schooling, household income, and untreated dental caries with the overall B-ECOHIS score. Internal consistency was assessed by Cronbach's alpha for the questionnaire and for the categories. 


\section{Ethical aspects}

This study complied with Brazilian Resolution No. 466 (2012) and was approved by the Human Research Ethics Committee of Fluminense Federal University.

All parents received information regarding the objectives of the study and signed an informed consent form.

\section{Results}

A total of 134 children with SHCN were initially enrolled in the study, but 128 (95.5\%) eventually participated in the study. Losses occurred due to the absence of a questionnaire filled out by the parents. Most of the questionnaires were answered by mothers $(87.5 \%)$. The mean (standard deviation) and median age of the children was $5.5( \pm 2.22)$ and 5.0 years, respectively, of whom $69(53.9 \%)$ were $<6$ years old, 89 (69.5\%) were male, and 51 (38.9\%) had autism spectrum disorder. Eighty-four parents (66.1\%) had more than eight years of education, and $<2$ BMW was more frequently $(64.4 \%)$ reported by parents. Untreated caries was prevalent in 57 children (44.5\%). Among children with caries, moderate severity (1 to 2 lesions) was observed in $29(22.7 \%)$ and high severity ( $\geq 3$ lesions) in 28 (21.9\%).

Most parents/caregivers reported an impact on OHRQoL (68.75\%) (B-ECOHIS score $>0$ ). Parents reported more impacts (B-ECOHIS score $>0$ ) related to the child (69.5\%) than to the family (49.6\%). Overall, B-ECOHIS scores ranged from 0 to 38 (CIS 0-31 and FIS 0-14). Table 1 displays the distribution of the answers to each B-ECOHIS item in each domain. The B-ECOHIS items with high means corresponding to some type of impact on OHRQoL were 'pain in the teeth, mouth, or jaws' (28.1\%) in the CIS and 'been upset' $^{\prime}(29.1 \%)$ in the FIS. Yet, higher mean values were observed for the function domain in the CIS.

The distribution of the means for each B-ECOHIS domain demonstrates that age, untreated dental caries, and caries severity were significantly associated with an impact on the OHRQoL of the children and

Table 1. Distribution of B-ECOHIS answers given by parents in population-based sample.

\begin{tabular}{|c|c|c|c|}
\hline \multirow{2}{*}{ Impacts } & Never or hardly ever & Occasionally, often or very often & Don't know \\
\hline & $N(\%)$ & $N(\%)$ & N (\%) \\
\hline \multicolumn{4}{|l|}{$\mathrm{CIS}$} \\
\hline \multicolumn{4}{|l|}{ Symptoms domain } \\
\hline Oral/dental pain & $91(71.1)$ & $36(28.1)$ & $1(0.8)$ \\
\hline \multicolumn{4}{|l|}{ Function domain } \\
\hline Difficulty drinking & $92(71.9)$ & $36(28.1)$ & $0(0)$ \\
\hline Difficulty eating & $95(74.2)$ & $33(25.8)$ & $0(0)$ \\
\hline Difficulty pronouncing words & $108(84.4)$ & $20(15.6)$ & $0(0)$ \\
\hline Missed preschool or school & $110(85.9)$ & $18(14.1)$ & $0(0)$ \\
\hline \multicolumn{4}{|l|}{ Psychological domain } \\
\hline Trouble sleeping & $106(82.8)$ & $22(17.2)$ & $0(0)$ \\
\hline Irritable or frustrated & $93(72.6)$ & $34(26.6)$ & $1(0.8)$ \\
\hline \multicolumn{4}{|c|}{ Self-image/ social interaction domain } \\
\hline Avoided smiling or laughing & $116(90.6)$ & $12(9.4)$ & 0 \\
\hline Avoided talking & $118(92.2)$ & $10(7.8)$ & 0 \\
\hline \multicolumn{4}{|l|}{ FIS } \\
\hline \multicolumn{4}{|l|}{ Parents distress domain } \\
\hline Been upset & $90(70.9)$ & $38(29.1)$ & 0 \\
\hline Felt guilty & $96(75.0)$ & $31(24.2)$ & $1(0.8)$ \\
\hline \multicolumn{4}{|l|}{ Family function domain } \\
\hline Taken time off from work & $114(89.1)$ & $13(10.1)$ & $1(0.8)$ \\
\hline Financial impact & $111(86.7)$ & $11(11.7)$ & $2(1.6)$ \\
\hline
\end{tabular}


of their families. Age showed significant results for the symptoms and function domains of the CIS and for the parent distress domain of the FIS. The highest means were obtained for children aged $>6$ years. Untreated dental caries and caries severity showed that the impact was associated with CIS domains (except for the self-image/social interaction domain). Likewise, the highest means were detected in the group with untreated dental caries $(\geq 1)$ and with high severity of dental caries (Table 2).

Table 2. Mean scores in B-ECOHIS domains according to socioeconomic factors, characteristics of the children, and oral conditions.

\begin{tabular}{|c|c|c|c|c|c|c|c|c|c|c|}
\hline \multirow{3}{*}{ Variable } & \multirow{3}{*}{$\mathrm{N}(\%)$} & \multirow{3}{*}{ SYD } & \multirow{3}{*}{ FD } & \multirow{3}{*}{ PD } & \multirow{3}{*}{ SSD } & CIS & \multirow{3}{*}{ PDD } & \multirow{3}{*}{ FFD } & FIS & Overall \\
\hline & & & & & & B-ECOHIS & & & B-ECOHIS & B-ECOHIS \\
\hline & & & & & & score & & & score & Score \\
\hline \multicolumn{11}{|l|}{ Age } \\
\hline$<6$ years & $\begin{array}{c}69 \\
(53.9)\end{array}$ & $\begin{array}{c}0.53 \\
(0.86)\end{array}$ & $\begin{array}{c}2.38 \\
(3.35)\end{array}$ & $\begin{array}{c}1.21 \\
(1.87)\end{array}$ & $\begin{array}{c}0.97 \\
(1.86)\end{array}$ & $\begin{array}{c}4.89 \\
(6.88)\end{array}$ & $\begin{array}{c}1.41 \\
(2.24)\end{array}$ & $\begin{array}{c}0.95 \\
(1.54)\end{array}$ & $\begin{array}{c}2.36 \\
(3.58)\end{array}$ & $\begin{array}{c}7.28 \\
(9.97)\end{array}$ \\
\hline$\geq 6$ years & $\begin{array}{c}59 \\
(46.1)\end{array}$ & $\begin{array}{c}1.13 \\
(1.21)\end{array}$ & $\begin{array}{c}2.82 \\
(2.78)\end{array}$ & $\begin{array}{c}1.48 \\
(1.70)\end{array}$ & $\begin{array}{c}0.58 \\
(1.10)\end{array}$ & $\begin{array}{c}6.01 \\
(5.40)\end{array}$ & $\begin{array}{c}1.58 \\
(1.80)\end{array}$ & $\begin{array}{c}0.58 \\
(1.07)\end{array}$ & $\begin{array}{c}2.17 \\
(2.43)\end{array}$ & $\begin{array}{c}8.23 \\
(7.16)\end{array}$ \\
\hline $\mathrm{p}$-value & & 0.010 & 0.022 & 0.169 & 0.307 & 0.017 & 0.002 & 0.203 & 0.002 & 0.003 \\
\hline \multicolumn{11}{|l|}{ Sex } \\
\hline Male & $\begin{array}{c}89 \\
(69.5)\end{array}$ & $\begin{array}{c}1.03 \\
(1.19)\end{array}$ & $\begin{array}{c}2.35 \\
(2.47)\end{array}$ & $\begin{array}{c}1.13 \\
(1.43)\end{array}$ & $\begin{array}{c}0.43 \\
(0.94)\end{array}$ & $\begin{array}{c}4.95 \\
(4.46)\end{array}$ & $\begin{array}{c}1.33 \\
(1.83)\end{array}$ & $\begin{array}{c}0.57 \\
(1.17)\end{array}$ & $\begin{array}{c}1.90 \\
(2.54)\end{array}$ & $\begin{array}{c}6.90 \\
(6.33)\end{array}$ \\
\hline Female & $\begin{array}{c}39 \\
(30.5)\end{array}$ & $\begin{array}{c}1.32 \\
(1.25)\end{array}$ & $\begin{array}{c}3.42 \\
(3.16)\end{array}$ & $\begin{array}{c}2.05 \\
(1.93)\end{array}$ & $\begin{array}{c}0.79 \\
(1.32)\end{array}$ & $\begin{array}{c}7.58 \\
(6.30)\end{array}$ & $\begin{array}{c}1.89 \\
(1.73)\end{array}$ & $\begin{array}{c}0.58 \\
(0.90)\end{array}$ & $\begin{array}{c}2.47 \\
(2.25)\end{array}$ & $\begin{array}{c}10.1 \\
(7.98)\end{array}$ \\
\hline$p$-value & & 0.387 & 0.309 & 0.170 & 0.579 & 0.245 & 0.682 & 0.785 & 0.897 & 0.343 \\
\hline \multicolumn{11}{|c|}{ Parent's/caregiver's schooling* } \\
\hline$\leq 8$ years & $\begin{array}{c}40 \\
(33.9)\end{array}$ & $\begin{array}{c}1.33 \\
(1.23)\end{array}$ & $\begin{array}{c}2.75 \\
(2.96)\end{array}$ & $\begin{array}{c}1.67 \\
(2.19)\end{array}$ & $\begin{array}{c}0.67 \\
(1.30)\end{array}$ & $\begin{array}{c}6.42 \\
(6.56)\end{array}$ & $\begin{array}{c}2.00 \\
(2.00)\end{array}$ & $\begin{array}{c}0.33 \\
(0.89)\end{array}$ & $\begin{array}{c}2.33 \\
(2.54)\end{array}$ & $\begin{array}{c}8.75 \\
(8.64)\end{array}$ \\
\hline$>8$ years & $\begin{array}{c}78 \\
(66.1)\end{array}$ & $\begin{array}{c}1.08 \\
(1.21)\end{array}$ & $\begin{array}{c}2.77 \\
(2.76)\end{array}$ & $\begin{array}{c}1.43 \\
(1.52)\end{array}$ & $\begin{array}{c}0.54 \\
(1.04)\end{array}$ & $\begin{array}{c}5.82 \\
(4.98)\end{array}$ & $\begin{array}{c}1.41 \\
(1.72)\end{array}$ & $\begin{array}{c}0.65 \\
(1.11)\end{array}$ & $\begin{array}{c}2.05 \\
(2.42)\end{array}$ & $\begin{array}{c}7.95 \\
(6.67)\end{array}$ \\
\hline p-value & & 0.664 & 0.269 & 0.081 & 0.415 & 0.221 & 0.356 & 0.225 & 0.216 & 0.262 \\
\hline \multicolumn{11}{|c|}{ Household income* } \\
\hline$<2 \mathrm{MW}$ & $\begin{array}{c}76 \\
(64.4)\end{array}$ & $\begin{array}{c}1.13 \\
(1.23)\end{array}$ & $\begin{array}{c}2.76 \\
(2.57)\end{array}$ & $\begin{array}{c}1.45 \\
(1.77)\end{array}$ & $\begin{array}{c}0.74 \\
(1.24)\end{array}$ & $\begin{array}{c}6.08 \\
(5.56)\end{array}$ & $\begin{array}{c}1.58 \\
(2.00)\end{array}$ & $\begin{array}{c}0.45 \\
(1.12)\end{array}$ & $\begin{array}{c}2.03 \\
(2.72)\end{array}$ & $\begin{array}{c}8.16 \\
(7.53)\end{array}$ \\
\hline$\geq 2 \mathrm{MW}$ & $\begin{array}{c}42 \\
(35.6)\end{array}$ & $\begin{array}{c}1.17 \\
(1.20)\end{array}$ & $\begin{array}{c}2.78 \\
(3.19)\end{array}$ & $\begin{array}{c}1.56 \\
(1.58)\end{array}$ & $\begin{array}{c}0.28 \\
(0.75)\end{array}$ & $\begin{array}{c}5.78 \\
(5.10)\end{array}$ & $\begin{array}{c}1.50 \\
(1.43)\end{array}$ & $\begin{array}{c}0.78 \\
(0.94)\end{array}$ & $\begin{array}{c}2.28 \\
(1.84)\end{array}$ & $\begin{array}{c}8.11 \\
(6.53)\end{array}$ \\
\hline p-value & & 0.894 & 0.986 & 0.558 & 0.208 & 0.911 & 0.537 & 0.054 & 0.836 & 0.952 \\
\hline \multicolumn{11}{|c|}{ Untreated dental caries } \\
\hline 0 & $\begin{array}{c}71 \\
(55.5)\end{array}$ & $\begin{array}{c}0.48 \\
(0.82)\end{array}$ & $\begin{array}{c}1.89 \\
(2.54)\end{array}$ & $\begin{array}{c}0.84 \\
(1.63)\end{array}$ & $\begin{array}{c}0.49 \\
(1.24)\end{array}$ & $\begin{array}{c}3.70 \\
(5.33)\end{array}$ & $\begin{array}{c}1.09 \\
(1.98)\end{array}$ & $\begin{array}{c}0.64 \\
(1.45)\end{array}$ & $\begin{array}{c}1.72 \\
(3.12)\end{array}$ & $\begin{array}{c}5.44 \\
(7.63)\end{array}$ \\
\hline$\geq 1$ & $\begin{array}{c}57 \\
(44.5)\end{array}$ & $\begin{array}{c}1.16 \\
(1.22)\end{array}$ & $\begin{array}{c}3.05 \\
(3.05)\end{array}$ & $\begin{array}{c}1.73 \\
(1.77)\end{array}$ & $\begin{array}{c}0.80 \\
(1.56)\end{array}$ & $\begin{array}{c}6.75 \\
(6.28)\end{array}$ & $\begin{array}{c}1.82 \\
(2.17)\end{array}$ & $\begin{array}{c}0.79 \\
(1.28)\end{array}$ & $\begin{array}{c}2.61 \\
(2.92)\end{array}$ & $\begin{array}{c}9.45 \\
(8.44)\end{array}$ \\
\hline$p$-value & & 0.001 & 0.008 & $<0.001$ & 0.103 & $<0.001$ & 0.017 & 0.171 & 0.008 & $<0.001$ \\
\hline \multicolumn{11}{|l|}{ Caries Severity } \\
\hline Caries-free & $\begin{array}{c}71 \\
(55.5)\end{array}$ & $\begin{array}{c}0.48 \\
(0.82)\end{array}$ & $\begin{array}{c}1.89 \\
(2.54)\end{array}$ & $\begin{array}{c}0.84 \\
(1.63)\end{array}$ & $\begin{array}{c}0.50 \\
(1.24)\end{array}$ & $\begin{array}{c}3.70 \\
(5.39)\end{array}$ & $\begin{array}{c}1.09 \\
(1.98)\end{array}$ & $\begin{array}{c}0.64 \\
(1.46)\end{array}$ & $\begin{array}{c}1.72 \\
(3.12)\end{array}$ & $\begin{array}{c}5.43 \\
(7.63)\end{array}$ \\
\hline Moderate & $\begin{array}{c}29 \\
(22.7)\end{array}$ & $\begin{array}{c}1.00 \\
(1.22)\end{array}$ & $\begin{array}{c}2.84 \\
(2.53)\end{array}$ & $\begin{array}{c}1.36 \\
(1.44)\end{array}$ & $\begin{array}{c}0.71 \\
(1.21)\end{array}$ & $\begin{array}{c}5.91 \\
(5.37)\end{array}$ & $\begin{array}{c}1.68 \\
(2.04)\end{array}$ & $\begin{array}{c}1.14 \\
(1.56)\end{array}$ & $\begin{array}{c}2.82 \\
(3.38)\end{array}$ & $\begin{array}{c}8.82 \\
(8.10)\end{array}$ \\
\hline High & $\begin{array}{c}28 \\
(21.9)\end{array}$ & $\begin{array}{c}1.32 \\
(1.22)\end{array}$ & $\begin{array}{c}3.27 \\
(3.52)\end{array}$ & $\begin{array}{c}2.11 \\
(2.01)\end{array}$ & $\begin{array}{c}0.90 \\
(1.87)\end{array}$ & $\begin{array}{c}7.60 \\
(7.07)\end{array}$ & $\begin{array}{c}1.96 \\
(2.32)\end{array}$ & $\begin{array}{c}0.43 \\
(0.80)\end{array}$ & $\begin{array}{c}2.40 \\
(2.41)\end{array}$ & $\begin{array}{c}10.1 \\
(8.87)\end{array}$ \\
\hline p-value & & 0.001 & 0.029 & 0.001 & 0.262 & 0.001 & 0.058 & 0.137 & 0.030 & 0.001 \\
\hline $\begin{array}{l}\text { Total mean } \\
\text { (SD) }\end{array}$ & $\begin{array}{c}128 \\
(100)\end{array}$ & $\begin{array}{c}0.77 \\
(1.06)\end{array}$ & $\begin{array}{c}2.36 \\
(2.82)\end{array}$ & $\begin{array}{c}1.24 \\
(1.74)\end{array}$ & $\begin{array}{c}0.62 \\
(1.39)\end{array}$ & $\begin{array}{c}4.97 \\
(5.91)\end{array}$ & $\begin{array}{c}1.43 \\
(2.08)\end{array}$ & $\begin{array}{c}0.69 \\
(1.37)\end{array}$ & $\begin{array}{c}2.13 \\
(3.02)\end{array}$ & $\begin{array}{l}7.10 \\
(8.17)\end{array}$ \\
\hline
\end{tabular}

SYD: symptoms domain (score range 0 to 4); FD: function domain (score range 0 to 16); PD: psychological domain (score range 0 to 8); SSD: self-image/social interaction domain (score range 0 to 8); PDD: parents distress domain (score range 0 to 8); FFD: family function domain (score range 0 to 8); MW: minimum wage.Data expressed as mean (SD); Mann-Whitney Y-test. *Missing data $=10$. 
Impact of untreated dental caries on oral health-related quality of life of children with special health care needs

Correlation between variables and the overall B-ECOHIS score was calculated based on 128 subjects, showing a significant relationship between age/untreated dental caries and B-ECOHIS scores $(r=0.218, p=0.01 ; r=0.333, p=<0.001$, respectively $)$ (Table 3). In the final multivariate model, a negative impact on OHRQoL was associated with untreated dental caries/caries severity and CIS/overall B-ECOHIS score (Table 4). Cronbach's alpha was 0.86 for the questionnaire as a whole.
Table 3. Correlation values between the B-ECOHIS and variables.

\begin{tabular}{lcc}
\hline \multirow{2}{*}{ Variable } & \multicolumn{2}{c}{ Overall B-ECOHIS score } \\
\cline { 2 - 3 } & $\begin{array}{c}\text { Correlation } \\
\text { coefficient }\end{array}$ & p-value \\
\hline Age & 0.218 & 0.01 \\
Sex & 0.080 & 0.37 \\
Parent's/caregiver's schooling & 0.109 & 0.24 \\
Household income & 0.108 & 0.24 \\
Untreated dental caries & 0.333 & $<0.001$ \\
\hline
\end{tabular}

Point-biserial correlation: Pearson's correlation coefficient.

Table 4. Final Poisson regression model for covariates associated with the CIS, FIS, and overall B-ECOHIS score.

\begin{tabular}{|c|c|c|c|}
\hline \multirow{2}{*}{ Covariates } & $\mathrm{CIS}$ & FIS & Overall B-ECOHIS score \\
\hline & Robust PR $(95 \% \mathrm{Cl})$ & Robust PR (95\%Cl) & Robust PR $(95 \% \mathrm{Cl})$ \\
\hline \multicolumn{4}{|c|}{ Socioeconomic factors } \\
\hline \multicolumn{4}{|c|}{ Parent's/caregiver's schooling } \\
\hline$\leq 8$ years & 1 & 1 & 1 \\
\hline$>8$ years & $1.40(0.83-2.37)$ & $1.22(0.67-2.22)$ & $1.21(0.76-1.93)$ \\
\hline $\mathrm{p}$-value & 0.20 & 0.51 & 0.64 \\
\hline \multicolumn{4}{|c|}{ Household income } \\
\hline$<2 \mathrm{MW}$ & 1 & 1 & 1 \\
\hline$\geq 2 \mathrm{MW}$ & $0.84(0.52-1.34)$ & $0.87(0.52-1.46)$ & $0.81(0.52-1.24)$ \\
\hline $\mathrm{p}$-value & 0.46 & 0.61 & 0.33 \\
\hline \multicolumn{4}{|c|}{ Characteristics of the children } \\
\hline \multicolumn{4}{|l|}{ Age } \\
\hline$<6$ years & 1 & 1 & 1 \\
\hline$\geq 6$ years & $1.54(0.94-2.55)$ & $1.60(0.90-2.83)$ & $1.10(0.74-1.63)$ \\
\hline$p$-value & 0.08 & 0.10 & 0.64 \\
\hline \multicolumn{4}{|l|}{ Sex } \\
\hline Male & 1 & 1 & 1 \\
\hline Female & $1.13(0.73-1.76)$ & $0.85(0.51-1.43)$ & $1.19(0.80-1.77)$ \\
\hline $\mathrm{p}$-value & 0.57 & 0.56 & 0.38 \\
\hline \multicolumn{4}{|c|}{ Oral clinical conditions } \\
\hline \multicolumn{4}{|c|}{ Untreated dental caries } \\
\hline 0 & 1 & 1 & 1 \\
\hline$\geq 1$ & $1.89(1.22-2.92)$ & $1.49(0.90-2.46)$ & $1.67(1.12-2.49)$ \\
\hline$p$-value & 0.004 & 0.120 & 0.011 \\
\hline \multicolumn{4}{|l|}{ Severity } \\
\hline Caries-free & 1 & 1 & 1 \\
\hline Moderate & $1.60(0.96-2.67)$ & $1.60(0.88-2.90)$ & $1.54(0.97-2.46)$ \\
\hline High & $2.17(1.31-3.60)$ & $1.37(0.79-2.38)$ & $1.81(1.15-2.86)$ \\
\hline $\mathrm{p}$-value & 0.009 & 0.277 & 0.031 \\
\hline
\end{tabular}

PR: prevalence ratio, calculated using Wald's chi-square test; MW: minimum wage. 


\section{Discussion}

This study evaluates the impact of untreated dental caries, sex, age, and socioeconomic factors on the OHRQoL of children with SHCN. However, few studies have assessed the OHRQoL of children with SHCN. ${ }^{4,5}$ Furthermore, other studies have assessed the impact of dental caries on OHRQoL, as well as the perception of parents about dental caries, but they have not focused on untreated dental caries. ${ }^{4,5,8,9} \mathrm{~B}$-ECOHIS is widely used in studies with preschool children. ${ }^{23,24}$ It was assumed that the subjects involved in the study lacked self-perception and that the application of B-ECOHIS would be pertinent. The instrument was used in a previous study with children with special needs ${ }^{4}$ and presented positive results in relation to its respective objectives.

In the general pediatric population, the prevalence of untreated dental caries ranges from $46 \%$ to $53 \%$ in developing countries. ${ }^{25}$ An untreated dental caries prevalence of $44.5 \%$ was observed in the present study. Similar results were found in children with cerebral palsy. ${ }^{26}$ However, some studies involving individuals with SHCN may report higher ${ }^{4,5,6,7}$ or low caries prevalence rates. ${ }^{27}$ These studies used the WHO criteria considering decayed (d/D), filled (f/F), and missing $(\mathrm{m} / \mathrm{M})$ teeth, but in the present study only the component 'decayed - $d / D^{\prime}$ ' was used. This shows that the values of the DMFT index and of the simplified indices used in the current study may present numerical differences. Since the presence of caries has demonstrated an association with the impact on the quality of life of children and caregivers, when only untreated dental caries is considered, the impact may be greater than that indicated by the DMFT index. ${ }^{14}$

The results confirmed the association between the presence of dental caries and worse OHRQoL in children with $\mathrm{SHCN}$, as pointed out by previous surveys. ${ }^{4,8}$ In addition, caries severity had higher means for high severity in the overall B-ECOHIS score in accordance with some surveys. ${ }^{4,8,28}$

Age dichotomization allowed evaluating in which phases the impact may be more present in childhood, whether in younger (aged $<6$ years) or in older (aged $\geq 6$ years) children. In this study, the biggest impact was observed in children aged $>6$ years. The finding that older children have a greater chance of experiencing a negative impact on their OHRQoL seemingly stems from the fact that such children have caries in more advanced stages of decay and also have a greater capacity to communicate their parents about the effects of oral health conditions on their quality of life..$^{11,14}$

Parents with a lower socioeconomic status were more likely to rate their children's oral health as 'worse than that of other children. ${ }^{29}$ Low-income caregivers tended to report higher scores, as also found in other studies. ${ }^{4,8,30}$ A study carried out in the highlands of the state of Rio de Janeiro also showed lack of a statistically significant association between family income and OHRQoL, ${ }^{5}$ as pointed out in this study (the referenced study did not use the ECOHIS). Most parents reported some impact on the quality of life of their children, indicating that this impact is stronger on the child than on the family. These findings are consistent with the extant literature., 12 The prevalence of impact on children's quality of life (CIS) in the present study (69.5\%) was similar to that reported in a previous study involving children and parents who sought treatment at a dental school $(69.3 \%) .{ }^{8}$ Our study showed that among the children whose quality of life was negatively affected, the most frequently reported impacts regarded 'pain in the teeth, mouth, or jaws'. In the FIS, the 'been upset' item was the most widely reported one. These results are consistent with other studies on this issue. ${ }^{428}$

This study shows a positive yet weak correlation between untreated dental caries and its impact on quality of life. A previous study performed with adolescents with juvenile idiopathic arthritis found no significant correlation between dental caries and OHRQoL. ${ }^{9}$ However, in line with the above-mentioned findings, another research paper showed a significant and weak correlation between dental caries and quality of life. ${ }^{31}$ Yet, this study is probably the first to correlate demographic and oral condition variables with OHRQoL for this population. Furthermore, there are few epidemiological studies on oral health directed towards children with SHCN.

The present study has limitations inherent to its cross-sectional design for having grouped all children 
with disabilities with their various incapacitating conditions into one single group (the systemic conditions of the evaluated children have very different limitations). Therefore, some individuals have very limited verbal ability, while others may be capable of expressing their discomfort or reason for being 'upset'. Furthermore, the diagnosis must have impacted their oral health, their quality of life, and the parents' ability to assess their children's quality of life. Also, the answers to the questionnaires might have been subject to information bias. In addition, although the pre-calculated sample size was reached and a margin of $17.5 \%$ was added to make up for possible losses, we considered the size of the nonrepresentative sample, assuming it as a convenience sample. Nonetheless, the use of a larger sample is suggested (categorizing children with $\mathrm{SHCN}$ into groups according to their medical condition / degree of intellectual disabilities) to confirm or disprove our results. A number of measures were taken to reduce the information bias, including the use of a validated questionnaire - one of the major strengths of the present study - and the undertaking of a pilot study.

\section{Conclusion}

In conclusion, untreated dental caries is associated with a negative impact on the OHRQoL of children with SHCN and of their families. Untreated dental caries and severity of dental caries showed an impact associated with the CIS domains (except for the self-image/social interaction domain). Better OHRQoL was reported in younger children and in families in which the parents had a lower level of schooling and income. An understanding of these influences can help clinicians and researchers assess oral health needs, establish priorities of care, and evaluate various treatment strategies, especially among children with SHCN.

\section{References}

1. American Academy of Pediatric Dentistry. Definition of special health care needs. Pediatr Dent. 2016 Oct;38(6):16.

2. Instituto Brasileiro de Geografia e Estatística - IBGE. Censo demográfico brasileiro. 2010 . [cited 2017 Dec]. Available from: http://www.ibge.gov.br

3. Faulks D, Norderyd J, Molina G, Macgiolla Phadraig C, Scagnet G, Eschevins $C$ et al. Using the International Classification of Functioning, Disability and Health (ICF) to describe children referred to special care or paediatric dental services. PLoS One. 2013 Apr;8(4):e61993. https://doi.org/10.1371/journal.pone.0061993

4. Aggarwal VP, Mathur A, Dileep CL, Batra M, Makkar DK. Impact of sociodemographic attributes and dental caries on quality of life of intellectual disabled children using ECOHIS. Int J Health Sci (Qassim). 2016 Oct;10(4):480-90. https://doi.org/10.12816/0048889

5. Alves NS, Gavina VP, Cortellazzi KL, Antunes LA, Silveira FM, Assaf AV. Analysis of clinical, demographic, socioeconomic, and psychosocial determinants of quality of life of persons with intellectual disability: a cross-sectional Study. Spec Care Dentist. 2016 Nov;36(6):307-14. https://doi.org/10.1111/scd.12196

6. Faker K, Di Lanaro N, Paula VA, Tostes MA.

Profile of special needs patients assisted in a dental project. Braz Dent Sci. 2016;4(4):14-20. https://doi.org/10.14295/bds.2016.v19i4.1300
7. Solanki J, Gupta S, Arya A. Dental caries and periodontal status of mentally handicapped institutilized children. J Clin Diagn Res. 2014 Jul;8(7):ZC25-7. https://doi.org/10.7860/JCDR/2014/8983.4557

8. Abanto J, Carvalho TS, Bönecker M, Ortega AO, Ciamponi AL, Raggio DP. Parental reports of the oral health-related quality of life of children with cerebral palsy. BMC Oral Health. 2012 Jun;12(1):15. https://doi.org/10.1186/1472-6831-12-15

9. Santos D, Silva C, Silva M. Oral health and quality of life of children and adolescents with juvenile idiopathic arthritis according to their caregivers' perceptions. Spec Care Dentist. 2015 Nov-Dec;35(6):272-8. https://doi.org/10.1111/scd.12129

10. Guedes RS, Piovesan C, Ardenghi TM, Emmanuelli B, Braga $M M$, Ekstrand KR et al. Validation of visual caries activity assessment: a 2-yr cohort study. J Dent Res. 2014 Jul;93(7 Suppl):101S-7S. https://doi.org/10.1177/0022034514531017

11. Fernandes IB, Ramos-Jorge J, Ramos-Jorge ML, Bönecker M, Abanto J, Marques LS et al. Correlation and comparative analysis of discriminative validity of the Scale of Oral Health Outcomes for Five-Year-Old Children (SOHO-5) and the Early Childhood Oral Health Impact Scale (ECOHIS) for dental caries. BMC Oral Health. 2015 Mar;15(1):29. https://doi.org/10.1186/s12903-015-0021-y 
12. Gomes MC, Clementino MA, Pinto-Sarmento TC, Costa EM, Martins CC, Granville-Garcia AF et al. Parental perceptions of oral health status in preschool children and associated factors. Braz Dent J. 2015 Jul-Aug;26(4):428-34. https://doi.org/10.1590/0103-6440201300245

13. Corrêa-Faria P, Paiva SM, Pordeus IA, Ramos-Jorge ML. Influence of clinical and socioeconomic indicators on dental trauma in preschool children. Braz Oral Res. 2015;29(1):1-7. https://doi.org/10.1590/1807-3107BOR-2015.vol29.0015

14. Ramos-Jorge J, Pordeus IA, Ramos-Jorge ML, Marques LS, Paiva SM. Impact of untreated dental caries on quality of life of preschool children: different stages and activity. Community Dent Oral Epidemiol. 2014 Aug;42(4):311-22. https://doi.org/10.1111/cdoe.12086

15. Souza JG, Souza SE, Noronha MS, Ferreira EF, Martins AM. Impact of untreated dental caries on the daily activities of children. J Public Health Dent. 2018 Jun;78(3):197-202. https://doi.org/10.1111/iphd.12259

16. Pahel BT, Rozier RG, Slade GD. Parental perceptions of children's oral health: the Early Childhood Oral Health Impact Scale (ECOHIS). Health Qual Life Outcomes. 2007 Jan;5(1):6. https://doi.org/10.1186/1477-7525-5-6

17. Scarpelli AC, Oliveira BH, Tesch FC, Leão AT, Pordeus IA, Paiva SM. Psychometric properties of the Brazilian version of the Early Childhood Oral Health Impact Scale (B-ECOHIS). BMC Oral Health. 2011 Jun;11(1):19. https://doi.org/10.1186/1472-6831-11-19

18. Cancio V, Faker K, Bendo CB, Paiva SM, Tostes MA. Individuals with special needs and their families' oral healthrelated quality of life. Braz Oral Res. 2018 May;32(0):e39. https://doi.org/10.1590/1807-3107bor-2018.vol32.0039

19. von Elm E, Altman DG, Egger M, Pocock SJ, Gøtzsche PC, Vandenbroucke JP. The Strengthening the Reporting of Observational Studies in Epidemiology (STROBE) statement: guidelines for reporting observational studies. J Clin Epidemiol. 2008 Apr;61(4):344-9. https://doi.org/10.1016/i.jclinepi.2007.11.008

20. Tesch FC, Oliveira BH, Leão A. [Semantic equivalence of the Brazilian version of the Early Childhood Oral Health Impact Scale]. Cad Saude Publica. 2008 Aug;24(8):1897-909. https://doi.org/10.1590/S0102-311X2008000800018

21. World Health Organization. Oral health surveys, basics methods. 5th ed. Geneva: World Health Organization; 2013.

22. Bratthal D. Introducing the Significant Caries Index together with a proposal for a new global oral health goal for 12-year-olds. Int Dent J. 2000;50(6):378-84 https://doi.org/10.1111/j.1875-595X.2000.tb00572.x

23. Li S, Malkinson S, Veronneau J, Allison PJ. Testing responsiveness to change for the early childhood oral health impact scale (ECOHIS). Community Dent Oral Epidemiol. 2008 Dec;36(6):542-8. https://doi.org/10.1111/j.1600-0528.2008.00434.x

24. Novaes TF, Pontes LR, Freitas JG, Acosta CP, Andrade KC, Guedes RS, et al.; CARDEC collaborative group. Responsiveness of the Early Childhood Oral Health Impact Scale (ECOHIS) is related to dental treatment complexity. Health Qual Life Outcomes. 2017 Sep;15(1):182. https://doi.org/10.1186/s12955-017-0756-z

25. Martins-Júnior PA, Vieira-Andrade RG, Corrêa-Faria P, Oliveira-Ferreira F, Marques LS, Ramos-Jorge ML. Impact of early childhood caries on the oral health-related quality of life of preschool children and their parents. Caries Res. 2013;47(3):211-8. https://doi.org/10.1159/000345534

26. De Camargo MA, Antunes JL. Untreated dental caries in children with cerebral palsy in the Brazilian context. Int J Paediatr Dent. 2008 Mar; 18(2):131-8. https://doi. org/10.1111/j.1365-263X.2007.00829.x

27. Nqcobo CB, Yengopal V, Rudolph MJ, Thekiso M, Joosab Z. Dental caries prevalence in children attending special needs schools in Johannesburg, Gauteng Province, South Africa. SADJ. 2012 Aug;67(7):308-13.

28. Chaffee BW, Rodrigues PH, Kramer PF, Vítolo MR, Feldens CA. Oral health-related quality-of-life scores differ by socioeconomic status and caries experience. Community Dent Oral Epidemiol. 2017 Jun;45(3):216-24. https://doi.org/10.1111/cdoe.12279

29. Piovesan C, Marquezan M, Kramer PF, Bönecker M, Ardenghi TM. Socioeconomic and clinical factors associated with caregivers' perceptions of children's oral health in Brazil. Community Dent Oral Epidemiol. 2011 Jun;39(3):260-7. https://doi.org/10.1111/j.1600-0528.2010.00598.x

30. Pani SC, Mubaraki SA, Ahmed YT, Alturki RY, Almahfouz SF. Parental perceptions of the oral healthrelated quality of life of autistic children in Saudi Arabia. Spec Care Dentist. 2013 Jan-Feb;33(1):8-12. https://doi.org/10.1111/j.1754-4505.2012.00294.x

31. Freitas AR, Aznar FD, Tinós AM, Yamashita JM, Sales-Peres A, Sales-Peres SH. Association between dental caries activity, quality of life and obesity in Brazilian adolescents. Int Dent J. 2014 Dec;64(6):318-23. https://doi.org/10.1111/idj.12121 